\title{
A left lung abscess with a displaced subsegmental bronchus and anomalous pulmonary artery and vein: a case report
}

\author{
Kazuto Ohtaka ${ }^{1 *}$ D, Nozomu Iwashiro ${ }^{1}$, Kazunori Watanabe ${ }^{1}$, Tomoko Mizota ${ }^{1}$, Ryo Takahashi ${ }^{1}$, Masato Suzuoki ${ }^{1}$, \\ Kazuteru Komuro', Masanori Ohara', Kichizo Kaga² and Yoshiro Matsui ${ }^{2}$
}

\begin{abstract}
Background: Since a displaced bronchus related to the left upper lobe is an uncommon anatomical anomaly, it has a risk of being accidentally resected during left upper lobe resection unless they are identified preoperatively. A case of video-assisted thoracic surgery (VATS) segmentectomy that was safely performed under preoperative identification of a displaced subsegmental bronchus and anomalous pulmonary vessels is presented.

Case presentation: A 48-year-old woman visited our hospital because of an abnormal shadow on a radiograph on a health check. The chest computed tomography (CT) showed a multicystic mass with a diameter of $35 \mathrm{~mm}$ on dorsal interlobar parenchyma between the $S^{1+2}$ and $S^{6}$ segments in the left lung. The three-dimensional (3D) $C T$ with multiplanar reconstruction showed that $\mathrm{B}^{1+2} \mathrm{~b}+\mathrm{c}$ passed to the dorsal side of the left main pulmonary artery $(P A)$, which was considered a displaced bronchus. The branch of $A^{6}$ arose from the left main PA at the level of the branches of $A^{3}$ and $A^{1+2}$, more proximal than the normal anatomy, and passed to the dorsal side of a displaced $B^{1+2} b+c$. The branch of $\mathrm{V}^{1+2}$ passed between $\mathrm{B}^{6}$ and the bronchus to the basal segment and joined $\mathrm{V}^{6}$ at the dorsal side of the pulmonary hilum. Intraoperative findings of the anatomy of the bronchi and pulmonary vessels were exactly the same as the preoperative 3DCT findings, so segmentectomy of $S^{1+2} b+c$ and $S^{6}$ by VATS was performed safely. Then there were accessory fissures between $S^{1+2}$ and $S^{3}$ and between $S^{6}$ and the basal segment. The pathological diagnosis was a left lung abscess.
\end{abstract}

Conclusions: A preoperative 3D CT may be helpful for identifying anatomical anomalies. An anatomical anomaly should be suspected if accessory fissure is found during surgery.

Keywords: Displaced bronchus, Eparterial bronchus, Pulmonary artery, Pulmonary vein, Accessory fissure, Anomaly, Variation, Preoperative diagnosis, Preoperative identification

\section{Background}

Abnormalities of the bronchi have been classified into supernumerary bronchi, displaced bronchi, and congenital cystic diseases [1]. The prevalence of these abnormalities is $0.64 \%$ [2]. In abnormalities of the bronchi, those related to the right upper lobe accounted for $75 \%$, and those related to the left upper lobe were rare [2]. The prevalence of a displaced bronchus to the left upper division demonstrated by bronchography is 0.3 to $0.5 \%[3,4]$.

\footnotetext{
* Correspondence: kit_katton0803@yahoo.co.jp

1 Department of Surgery, National Hospital Organization Hakodate National

Hospital, 18-16, Kawahara-cho, Hakodate, Hokkaido 041-8512, Japan

Full list of author information is available at the end of the article
}

Thus, a displaced subsegmental bronchus to the left upper division appears to be less common [5]. The most common displaced bronchus to the left upper division is that arises from the left main bronchus (LMB) and passes to the dorsal side of the left main pulmonary artery (PA) [6]. Therefore, unless this anatomical anomaly is identified preoperatively, a displaced bronchus can sometimes be accidentally resected while dividing the left upper and lower lobes $[7,8]$. A case in which video-assisted thoracic surgery (VATS) segmentectomy was safely performed under preoperative identification of a displaced subsegmental bronchus and anomalous PA and pulmonary vein $(\mathrm{PV})$ is presented. 


\section{Case presentation}

A 48-year-old woman with no smoking history visited another hospital twice because of cough, 5 and 9 years earlier. The chest X-ray and computed tomography (CT) showed a nodule with a diameter of about $20 \mathrm{~mm}$ in the left lung that was suspected to be a bronchial cyst. She had not since visited the hospital. She finally came to our hospital because of an abnormal shadow on a radiograph on a health check. The chest CT (Revolution EVO; GE Healthcare, Tokyo, Japan) showed a multicystic mass without irregular wall thickness and a diameter of $35 \mathrm{~mm}$ on the dorsal interlobar parenchyma between the $S^{1+2}$ and $S^{6}$ segments in the left lung (Fig. 1). The bronchoscopy showed that three bronchi branched from the $\mathrm{LMB}$, a branch of the lower lobe and two branches of the upper lobe (Fig. 2). No histological diagnosis was obtained by bronchoscopic biopsy. The three-dimensional (3D) CT with multiplanar reconstruction by a standalone workstation (SYNAPSE VINCENT; Fujifilm, Tokyo, Japan) showed that $\mathrm{B}^{1+2} \mathrm{~b}+\mathrm{c}$ passed to the dorsal side of the left main PA, which was considered a displaced bronchus (Fig. 3). The branch of $\mathrm{A}^{6}$ arose from the left main PA at the level of the branches of $\mathrm{A}^{3}$ and $\mathrm{A}^{1+2}$, more proximal than the normal anatomy, and passed to the dorsal side of the displaced $\mathrm{B}^{1+2} \mathrm{~b}+\mathrm{c}$. The branch of $\mathrm{V}^{1+2}$ passed between $\mathrm{B}^{6}$ and the bronchus to the basal segment and joined $\mathrm{V}^{6}$ at the dorsal side of the pulmonary hilum. Although the preoperative diagnosis predicted benign disease, a bronchial cyst, surgical resection was performed for the purpose of diagnosis because the multicystic mass had grown bigger with time. If it was diagnosed malignant such as lung cancer by postoperative pathological examination, additional surgery needs to be planned for mediastinal lymph node dissection.

Segmentectomy of $\mathrm{S}^{1+2} \mathrm{~b}+\mathrm{c}$ and $\mathrm{S}^{6}$ was performed by VATS with a $4 \mathrm{~cm}$ access thoracotomy at the fifth intercostal space of the anterior axillary line, a $1.5-\mathrm{cm}$ access port at the sixth intercostal space of the posterior axillary line, and a 5-mm camera port at the seventh intercostal space of the middle axillary line. There were accessory fissures between $S^{1+2}$ and $S^{3}$ and between $S^{6}$ and the basal segment that were largely fused. The intraoperative findings of the anatomy of the bronchi and pulmonary vessels were exactly the same as the preoperative CT findings (Fig. 4). At the cranial and dorsal sides of the pulmonary hilum, $\mathrm{A}^{6}$, which arose more proximal and passed to the dorsal side of the displaced $\mathrm{B}^{1+2} \mathrm{~b}+\mathrm{c}$, was divided. Then, the displaced $\mathrm{B}^{1+2} \mathrm{~b}+\mathrm{c}$ was readily identified, and $\mathrm{V}^{1+2}+\mathrm{V}^{6}$,

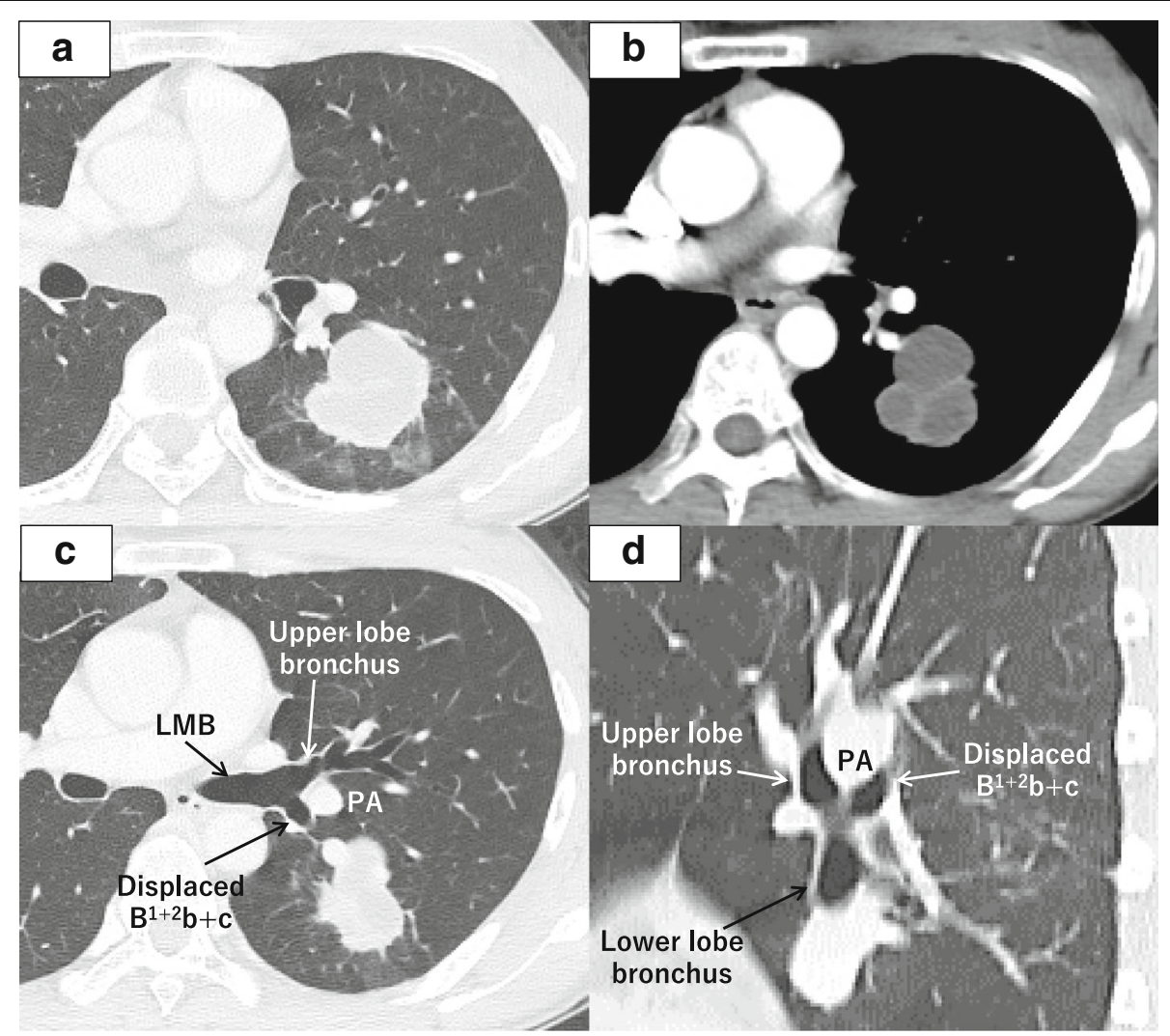

Fig. 1 Chest computed tomography. There is a multicystic mass with a diameter of $35 \mathrm{~mm}$ on the dorsal interlobar parenchyma between the $S^{1+2}$ and $S^{6}$ segments in the left lung $(\mathbf{a}, \mathbf{b})$. The displaced bronchus arises from the left main bronchus and passes to the dorsal side of the left main pulmonary artery (c, d). LMB, left main bronchus; PA, pulmonary artery 


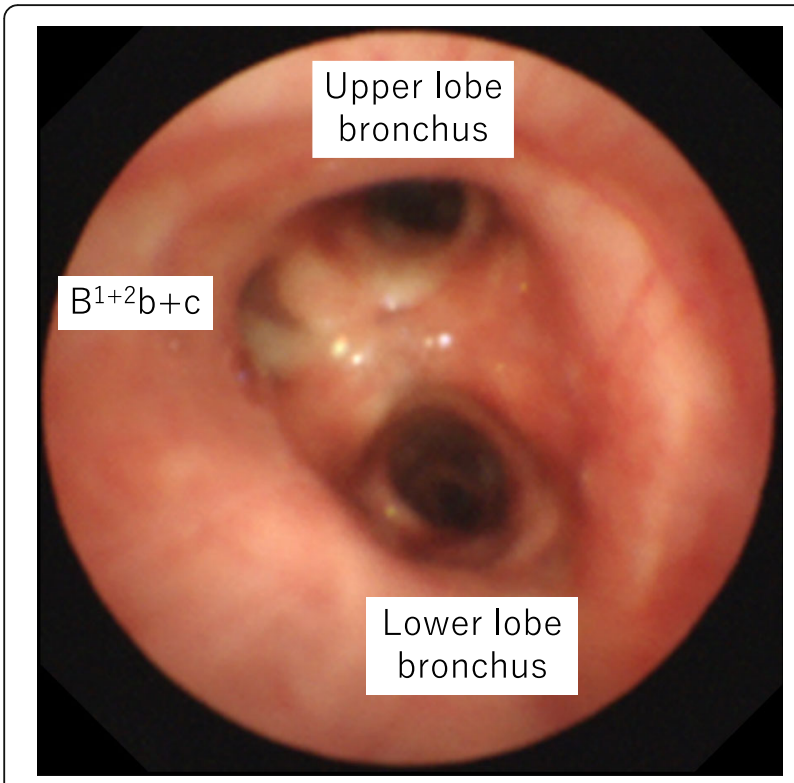

Fig. 2 Bronchoscopic imaging. There are three bronchi branched from the left main bronchus, a branch of the lower lobe and two branches of the upper lobe
$\mathrm{B}^{6}$ and the displaced $\mathrm{B}^{1+2} \mathrm{~b}+\mathrm{c}$ were divided in sequence. After dividing the largely fused accessory fissure between $\mathrm{S}^{6}$ and the basal segment by stapler, $\mathrm{A}^{1+2} \mathrm{c}$ and $\mathrm{A}^{1+2} \mathrm{~b}$ were divided. Finally, the largely fused accessory fissure between $\mathrm{S}^{1+2}$ and $\mathrm{S}^{3}$ was divided by stapler. The intersegmental line could be readily identified because of accessory fissures. If there was no accessory fissure, the technique that created a demarcation line between the inflated and deflated segment might be used. The operating time was $260 \mathrm{~min}$, and the blood loss was minimal. The patient's postoperative course was good. The pathological diagnosis was left lung abscess. The mass was a cyst connected to a bronchus. The wall structure was desquamated and replaced by the granulation tissue with inflammatory cells. Since there was no finding of a bronchial atresia in the resected specimen, the etiology of the lung abscess was considered as a bronchial cyst with recurrent infection.

\section{Discussion}

The anatomical features of the present case were as follows: (1) left $B^{1+2} b+c$ branched from LMB and passed to the dorsal side of the left main $\mathrm{PA}$, which was considered a displaced bronchus; (2) the branch of $\mathrm{A}^{6}$ arose from the more proximal point of the left main PA than in the normal anatomy and passed to the dorsal side of a displaced $\mathrm{B}^{1+2} \mathrm{~b}+\mathrm{c}$; (3) $\mathrm{V}^{1+2}$ passed between $\mathrm{B}^{6}$ and the bronchus to the basal segment and joined $\mathrm{V}^{6}$ at the dorsal side of the

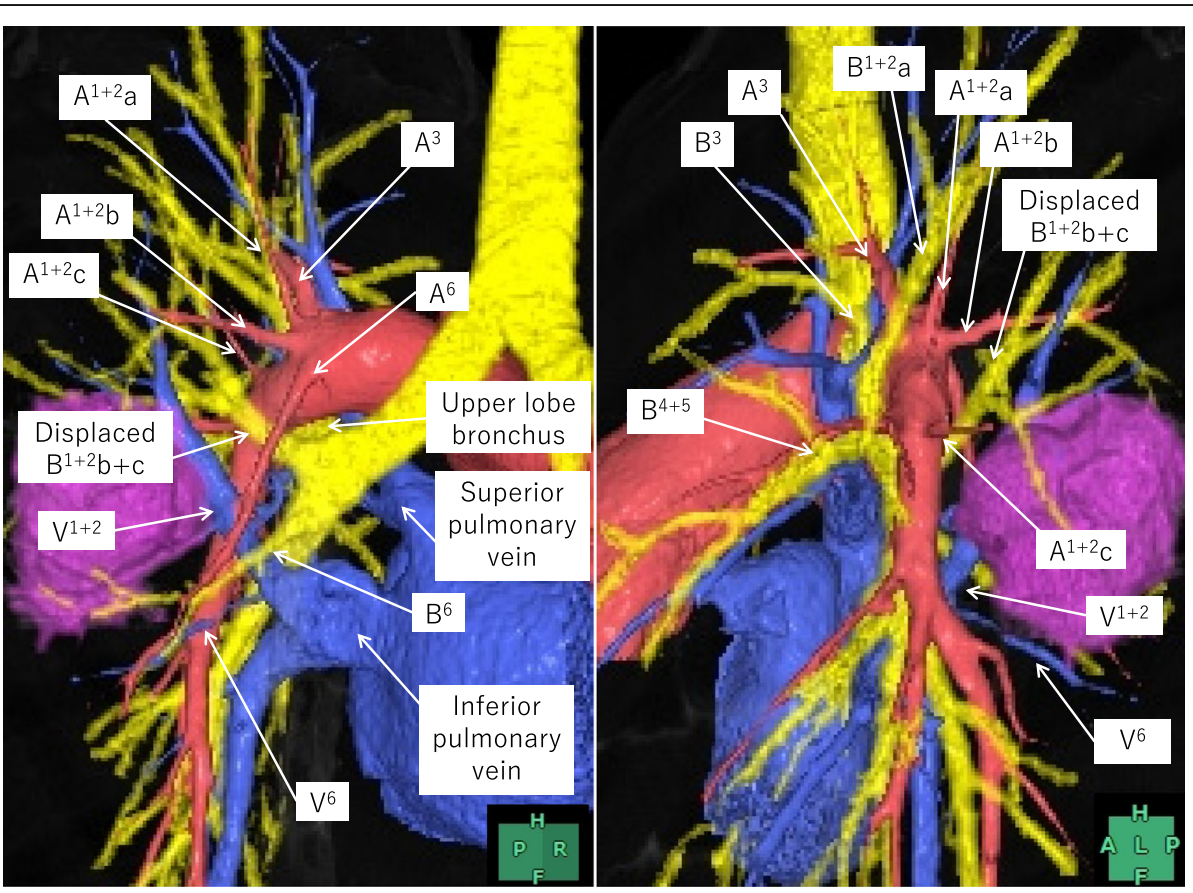

Fig. 3 Three-dimensional computed tomography with multiplanar reconstruction. The displaced $\mathrm{B}^{1+2} \mathrm{~b}+\mathrm{c}$ passes to the dorsal side of the left main pulmonary artery. The branch of $A^{6}$ arises from the left main pulmonary artery at the level of the branches of $A^{3}$ and $A^{1+2}$ and passes to the dorsal side of the displaced $\mathrm{B}^{1+2} \mathrm{~b}+\mathrm{c}$. The branch of $\mathrm{V}^{1+2}$ passes between $\mathrm{B}^{6}$ and the bronchus to the basal segment and joins $\mathrm{V}^{6}$ at the dorsal side of the pulmonary hilum 


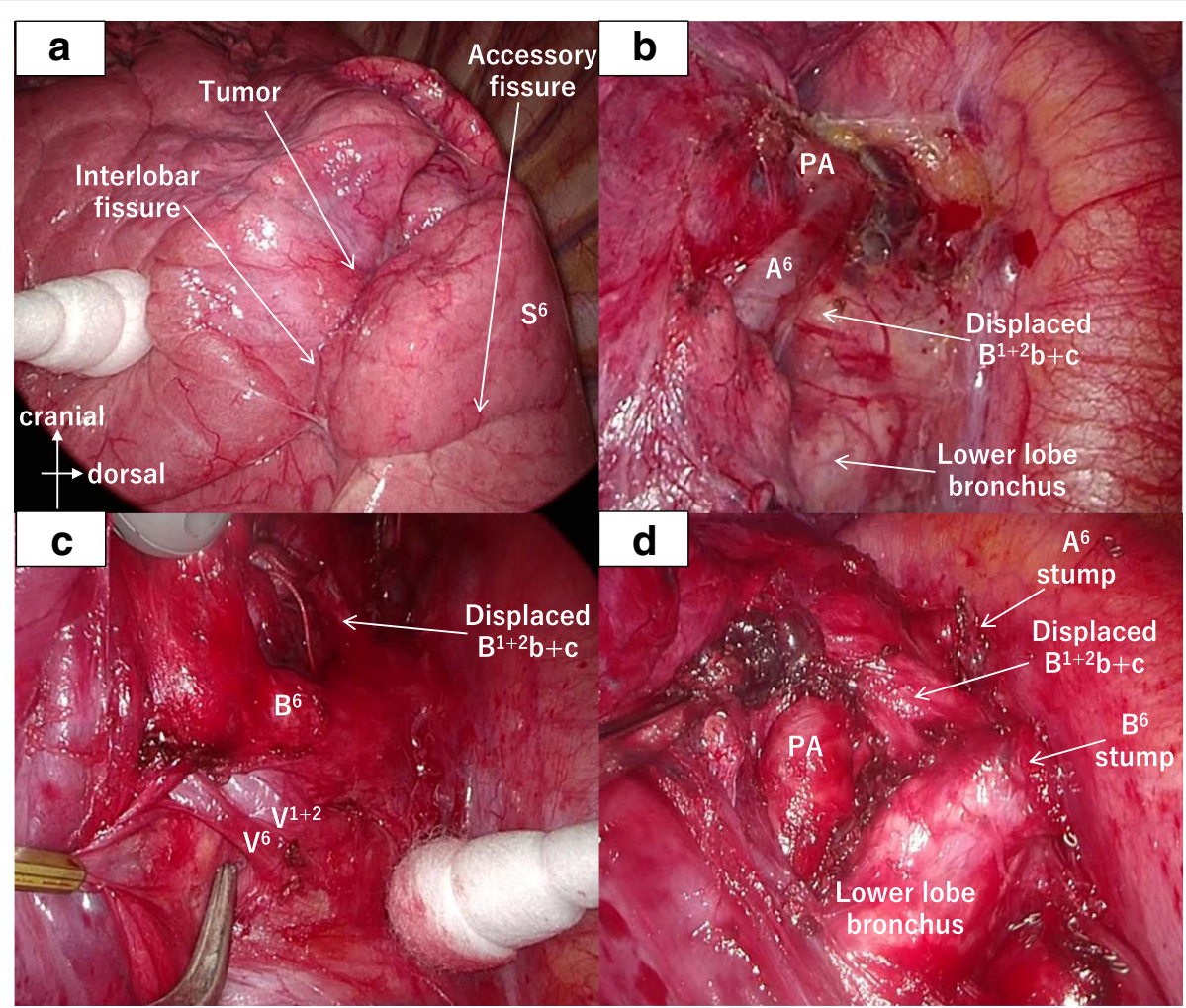

Fig. 4 Intraoperative findings. There are incomplete accessory fissures between $S^{1+2}$ and $S^{3}$ and between $S^{6}$ and the basal segment (a). The branch of $A^{6}$ arises from the more proximal point than a normal anomaly and passes to the dorsal side of the displaced $B^{1+2} b+c(\mathbf{b})$. The branch of $\mathrm{V}^{1+2}$ passes between $\mathrm{B}^{6}$ and the bronchus to the basal segment and joins $\mathrm{V}^{6}$ at the dorsal side of the pulmonary hilum $(\mathbf{c})$. The displaced $\mathrm{B}^{1+2} \mathrm{~b}+\mathrm{C}$ passes to the dorsal side of the main pulmonary artery (d)

pulmonary hilum; and (4) there were accessory fissures between $S^{1+2}$ and $S^{3}$ and between $S^{6}$ and the basal segment. Because these anatomical features were identified on the preoperative 3D CT, segmentectomy of $\mathrm{S}^{1+2} \mathrm{~b}+\mathrm{c}$ and $S^{6}$ by VATS was safely performed without misidentification of the anatomy.

With respect to aberrant bronchi to the left upper lobe, Ghaye et al. classified them as follows: (1) eparterial (true left tracheal) bronchi that arise from the trachea; (2) eparterial (left "tracheal") bronchi that arise from the posterosuperior aspect of the LMB and pass to the dorsal side of the left main PA; (3) prehyparterial bronchi that arise from the anterosuperior aspect of the LMB and pass to the ventral side of the left main PA; and (4) posthyparterial bronchi that arise from the bronchus to the left lower lobe (Fig. 5) [9]. Before the development of $\mathrm{CT}$, because the bronchus that passed to the dorsal side of the left main PA was identified by bronchography and intraoperative findings, it was called an eparterial bronchus [10, 11]. However, Oshiro et al. demonstrated that most of the origins of a displaced bronchus to the left upper division were lower than the inferior wall of the proximal PA on CT findings, and suggested that "eparterial bronchus" might not necessarily be the correct term [6].

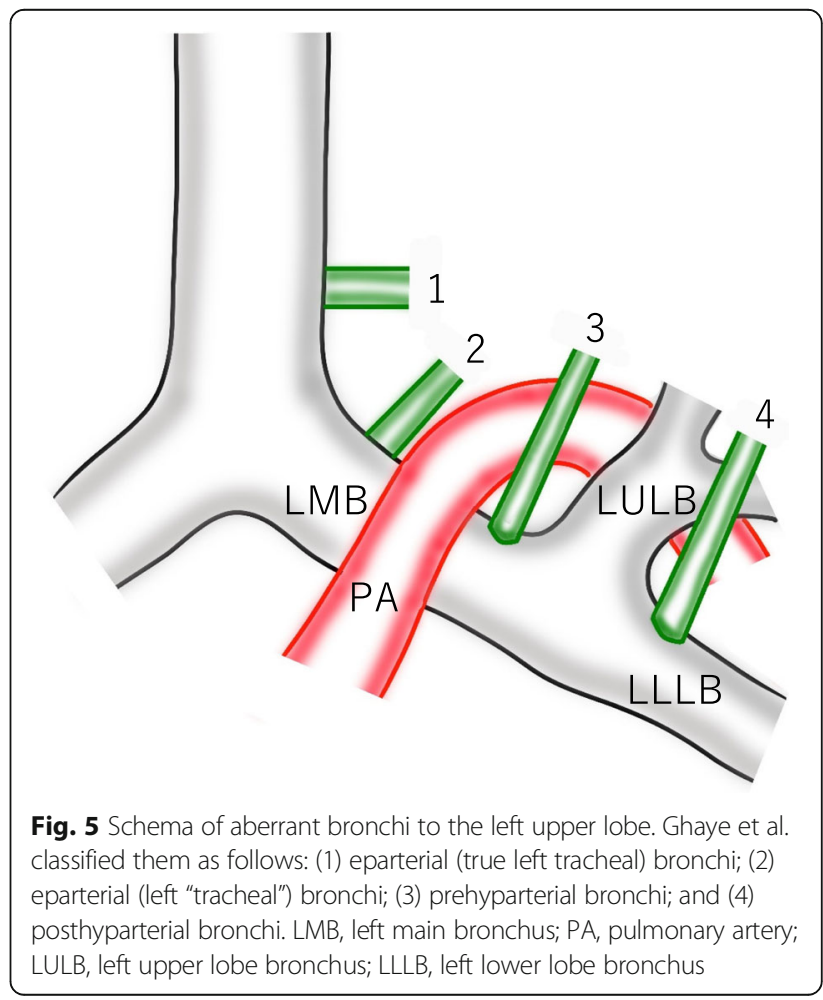


While recent reports commonly used the term "a displaced bronchus," "an eparterial bronchus" is an uncommon expression $[7,12]$. Furthermore, there was another rare anatomical variation that the PA passed between the bronchus to the upper division and the lingual division with normal bronchial anatomy, which was reported by Melloni et al. as a variation of the course of the left PA [13]. Boyden et al. reported five cases with an eparterial bronchus, of which four cases had an eparterial bronchus arising from the left upper bronchus but not from the LMB [14]. These anomalies also suggested the possibility of variation of the course of the left PA rather than a displaced bronchus. With respect to a bronchus for the left upper division that passes to the dorsal side of the left main PA, displacement of the bronchus must be distinguished from a variation of the course of the left PA.

The branch of left $\mathrm{A}^{6}$ commonly arises from the interlobar part of the left PA between the origin of the lowermost artery of $\mathrm{A}^{1+2}$ and the origin of $\mathrm{A}^{4+5}$ (the common trunk of lingular segmental arteries) [15]. In the present case, the branch of $\mathrm{A}^{6}$ took its origin at the same level of the uppermost artery of $\mathrm{A}^{1+2}$ and $\mathrm{A}^{3}$ and passed to the dorsal side of a displaced $\mathrm{B}^{1+2} \mathrm{~b}+\mathrm{c}$. Since the branch of $A^{6}$ was identified preoperatively, it was able to be immediately found at the cranial and dorsal side of the pulmonary hilum during surgery and safely divided. This type of anomalous $\mathrm{A}^{6}$ can be injured or confusing if it is not identified preoperatively.

In the report about variations of the course of the PV by Shiina et al., the prevalence on the left side was $2.6 \%$, which was less frequent than on the right side at $32.8 \%$ [16]. Among variations of the course of left $\mathrm{V}^{1+2}$, the variation that passed to the dorsal side of the pulmonary hilum and joined $\mathrm{V}^{6}$ or the inferior PV was more frequent than the others $[17,18]$. In the present case, the left $\mathrm{V}^{1+2}$ passed between $\mathrm{B}^{6}$ and the bronchus to the basal segment and joined $\mathrm{V}^{6}$ at the dorsal side of the pulmonary hilum. Without preoperative identification on the $3 \mathrm{D} \mathrm{CT}$, there is a high potential of misidentifying an anomalous $\mathrm{V}^{1+2}$ as $\mathrm{V}^{6}$. In recent years, a preoperative 3D CT has contributed to a better understanding of the courses of pulmonary vessels and bronchi [19]. Because there are rare and unexpected variations of these structures, a preoperative 3D CT should probably be considered a routine examination as long as there is no contraindication to the use of contrast dye.

In the present case, there were accessory fissures between $S^{1+2}$ and $S^{3}$ and between $S^{6}$ and the basal segment with incomplete lobulation. It has been reported that accessory fissures are incomplete in most cases [20]. Accessory fissures of the left upper lobe are common between the upper and lingular divisions, but rare between $S^{1+2}$ and $S^{3}$ [20]. Additionally, Oshiro et al. reported 10 cases with a displaced left upper division bronchus, of which 7 cases had an accessory fissure between the segment associated with a displaced bronchus and the remaining part of the left upper lobe [6]. An accessory fissure often coincides with an anatomical anomaly like a displaced bronchus [6]. In particular, if an accessory fissure is found between $S^{1+2}$ and $S^{3}$ during surgery, the presence of a displaced $\mathrm{B}^{1+2}$ that passes to the dorsal side of the left main PA must be suspected.

\section{Conclusions}

VATS segmentectomy was performed for a patient with a displaced subsegmental bronchus and anomalous pulmonary vessels. A preoperative 3D CT may be helpful for the identification of anatomical anomalies. Furthermore, one should be alert to the fact that an anatomical anomaly might be present if an accessory fissure is found during surgery.

\section{Abbreviations \\ LMB: Left main bronchus; PA: Pulmonary artery; VATS;: Video-assisted thoracoscopic surgery; CT: Computed tomography; 3D: Three-dimensional; PV: Pulmonary vein}

\section{Acknowledgements}

The authors would like to thank Noriko Kimura (Department of Pathology, National Hospital Organization Hakodate National Hospital).

\section{Funding}

None

\section{Availability of data and materials}

Data sharing is applicable to this article.

\section{Authors' contributions}

$\mathrm{KO}$ was the main surgeon and drafted the manuscript. NI assisted during the surgery and helped draft the manuscript. KW, TM, RT, MS, KK, and MO helped care for the patient and draft the manuscript. KK and YM reviewed and modified the manuscript. All authors read and approved the final manuscript.

Ethics approval and consent to participate Not applicable.

\section{Consent for publication}

Informed consent was obtained from the patient for the publication of this case report.

\section{Competing interests}

The authors declare that they have no competing interests.

\section{Publisher's Note}

Springer Nature remains neutral with regard to jurisdictional claims in published maps and institutional affiliations.

\section{Author details}

'Department of Surgery, National Hospital Organization Hakodate National Hospital, 18-16, Kawahara-cho, Hakodate, Hokkaido 041-8512, Japan.

${ }^{2}$ Department of Cardiovascular and Thoracic Surgery, Hokkaido University Graduate School of Medicine, Sapporo, Hokkaido, Japan. 
Received: 22 February 2019 Accepted: 10 April 2019

Published online: 23 April 2019

\section{References}

1. Foster-Carter AF. Broncho-pulmonary abnormalities. Br J Tuberc Dis Chest. 1946;40:111-24.

2. Ohta S, Saito Y, Usuda K, Kanma K, Sagawa M, Sato M, et al. Tracheobronchial anomalies: report of 71 cases. J Jpn Soc Resp Endoscopy. 1986:8:122-30 (in Japanese).

3. Le Roux BT. The bronchial anatomy of the left upper lobe. J Thorac Cardiovasc Surg. 1964;44:216-24.

4. Remy J, Smith M, Marache P, Nuyts JP. Pathogenetic left tracheal bronchus. A review of the literature in connection with four cases (author's transl). J Radiol Electrol Med Nucl. 1977;58:621-30 (in French).

5. Motohashi S, Yamaguchi Y, Takeda T, Aoyagi H, Ohtsuka T, Yokosuka T, et al. A case of lung squamous cell carcinoma in anomalously situated subsegmental bronchus of the left upper lobe; a case report. Jpn J Chest Surg. 1995;9:181-6 in Japanese.

6. Oshiro Y, Murayama S, Ohta M, Teruya T. CT findings of a displaced left upper division bronchus in adults: Its importance for performing safe left pulmonary surgery. Eur J Radiol. 2013;82:1347-52.

7. Shimamoto A, Takao M, Kodama H, Murashima S, Shomura S, Tarukawa T, et al. A case of left apicoposterio segmentectomy for lung cancer occurring in a displaced anomalous bronchus. J Jpn Soc Resp Endoscopy. 2008;30:210-4 (in Japanese).

8. Tsukioka T, Yamamoto R, Takahama M, Nakajima R, Tada H. A case of lung cancer arising from abnormal bronchi. J Japan Assoc Chest Surg. 2011;25: 460 (in Japanese)

9. Ghaye B, Szapiro D, Fanchamps JM, Dondelinger RF. Congenital bronchial abnormalities revised. Radiographics. 2001;21:105-19.

10. Wells JAT. A left eparterial bronchus and a tri-lobed left lung. a case report. Dis Chest. 1960;37:129-31.

11. Lynn RB. Left eparterial bronchus: a rare development anomaly of the bronchial tree. Can J Surg. 1960;4:74-5.

12. Asakura K, Imanishi N, Matsuoka T, Nagai S, Matsuoka K, Ueda M, et al. Video-assisted thoracic surgery lobectomy for lung cancer with displaced B1+2. Ann Thorac Cardiovasc Surg. 2014;20:486-9.

13. Melloni G, Cremona G, Carretta A, Ferla L, Bandiera A, Zannini P. A particular anatomic variation of the course of the left pulmonary artery. J Thorac Cardiovasc Surg. 2005;130:1719-20.

14. Boyden EA. Segmental anatomy of the lungs. New York: McGraw-Hill; 1955.

15. Topol M. Place of origin of the apical segmental artery of the left inferior lobe in relation to other branches arising from the interlober portion of the left pulmonary artery in human. Folia Morphol (Warsz). 1996:55:175-85.

16. Shiina N, Kaga K, Hida Y, Sasaki T, Hirano S, Matsui Y. Variations of pulmonary vein drainage critical for lung resection assessed by three-dimensional computed tomography angiography. Thorac Cancer. 2018;9:584-8.

17. Aragaki M, limura $Y$, Yoshida $Y$, Hasegawa N. Anomalous V2 of the left pulmonary vein detected using three-dimensional computed tomography in a patient with lung cancer: A case report. Int I Surg Case Rep. 2017;37:208-10

18. Ishikawa Y, Iwano S, Usami N, Yokoi K. An anomalous segmental vein of the left upper lobe of the lung: Preoperative identification by three-dimensional computed tomography pulmonary angiography. Interact Cardiovasc Thorac Surg. 2012;15:512-3.

19. Watanabe S, Arai K, Watanabe T, Koda W, Urayama H. Use of threedimensional computed tomographic angiography of pulmonary vessels for lung resections. Ann Thorac Surg. 2003;75:388-92.

20. Berkmen T, Berkmen YM, Austin JHM. Accessory fissures of the upper lobe of the left lung: CT and plain film appearance. AJR. 1994;162:1287-93.

\section{Submit your manuscript to a SpringerOpen ${ }^{\circ}$ journal and benefit from:}

- Convenient online submission

- Rigorous peer review

- Open access: articles freely available online

- High visibility within the field

- Retaining the copyright to your article

Submit your next manuscript at $\boldsymbol{\nabla}$ springeropen.com 